\title{
Non-corrosive and chlorine-free isomerisation process under supercritical conditions
}

\author{
B. Sander, M. Thelen, B. Kraushaar-Czarnetzki* \\ Institute of Chemical Process Engineering (CVT), University of Karlsruhe, D-76128 Karlsruhe, Germany
}

\begin{abstract}
Commercial processes presently applied to manufacture iso-butane from $n$-butane involve continuous co-feeding of chlorine compounds and of hydrogen to enhance the activity and stability of the Pt/alumina catalysts. Aiming for alternative options, we investigated the isomerisation of $n$-butane at supercritical conditions, using commercially available sulphated zirconia extrudates as a catalyst. As compared to gas-phase conditions, the stability of the catalyst and the production capacities of iso-butane, amounting up to $3.0 \mathrm{~kg}$ iso-butane $/ \mathrm{kg}$ catalyst and hour, could strongly be enhanced. Desulphurisation of the catalyst, causing release of hydrogen sulphide and concomitant catalyst deactivation, was observed at temperatures above $235^{\circ} \mathrm{C}$. Furthermore, the catalyst used in this study exhibited saturation behaviour. The results presented may point the way for the investigations and improvements necessary to make supercritical isomerisation an attractive processing alternative. () 2002 Elsevier Science B.V. All rights reserved.
\end{abstract}

Keywords: iso-Butane; Isomerisation; Sulphated zirconia; Supercritical catalysis

\section{Introduction}

iso-Butane (iso-C4) is a major feedstock for the manufacturing of gasoline blending components like motor fuel alkylate or methyl tertiary-butyl ether (MTBE). The demand for these components increased since 1963 when the first regulations about the gasoline lead content became effective in the United States. In nowadays, the environmental risks of MTBE are a matter of debate because the compound is not biodegradable and tends to accumulate in the ground water. Decreasing the concentration of MTBE in gasoline, however, will require the addition of more alkylate to attain a high motor octane number (MON) at low aromatics content. Hence, iso-C4 will con-

\footnotetext{
* Corresponding author.

E-mail address: Bettina.Kraushaar@ciw.uni-karlsruhe.de

(B. Kraushaar-Czarnetzki).
}

tinue being an important feedstock for reformulated gasoline.

Because the amounts of iso-C4 available as by-products from refinery processes such as fluid catalytic cracking (FCC) were not sufficient to meet the requirements, commercial processes have been developed by, for instance, UOP, BP, or ABB Lummus for the catalytic conversion of $n$-butane to iso-C4. The chemical reactions involved in these processes can be summarised with the term hydro-isomerisation. The catalysts used are bi-functional, consisting of platinum supported on alumina [1]. A small amount of organic chlorides is continuously co-fed to form a highly acidic aluminium chloride surface upon reaction with the alumina support. Platinum catalyses both, the dehydrogenation of $n$-butane to the much more reactive butenes, and the saturation of olefinic intermediates to paraffins. Hydrogen is present in the feed to keep the amounts of olefinic species on a low, 
quasi-stationary level, thereby suppressing the competing formation of oligomers and coke precursors. In the open literature, data on the operation conditions applied in the commercial processes are scarce. Reaction temperatures between 149 and $204{ }^{\circ} \mathrm{C}$ and pressures between 14 and 28 bar have been reported for Butane Isom (BP). [2]. According to an even earlier publication, Butamer (UOP) works at higher temperatures in the range of $315-454^{\circ} \mathrm{C}$ [3]. Generally, the processes are carried out in the gas phase, and high selectivities of iso-C4 $(>95 \%)$ are achievable at conversions close to the respective equilibrium values. However, it can be taken for granted that the references above are not reflecting the current state of the art because further development of the technology has been strongly promoted during the past decades. It can be assumed that catalysts employed today allow for lower, thermodynamically more favourable reactions temperatures (i.e., around $150^{\circ} \mathrm{C}$ ). Generally, chlorinated alumina catalysts are sensitive to contaminants like water, carbon oxides, and organic oxygenates, and platinum can be poisoned by sulphur compounds $[1,4]$. When suitable precautions are taken, catalyst life-times amount to about 2 years [2] and up to 6 years even, when an $\eta$-alumina is used instead of $\gamma$ alumina [5].

The current processes for the isomerisation of $n$-butane are efficient with respect to iso-C4 yields and runtime, and the technology employed is proven and well established. The search for alternatives is predominantly driven by the problems related to the continuous chlorination of the catalyst, e.g., precise control of the water content in the feed, release of $\mathrm{HCl}$, corrosion, disposal of salts from the scrubber, or regeneration of the $\mathrm{AlCl}_{3}$-containing catalyst.

An improved process, therefore, requires a chlorine-free, non-corrosive catalyst that is sufficiently active and selective in the isomerisation of $n$-butane. Sulphated zirconia (SZ) catalysts could meet these requirements as has been shown in numerous recent studies, e.g., in [6]. However, SZ, be it as such or in combination with transition metals, cannot compete with respect to stability because it is deactivated within minutes during gas-phase operation. Longer catalyst life-times of about $400 \mathrm{~h}$ were reported in the context of conversion experiments with supercritical $n$-butane by Bhinde and Hsu et al. [7]. The catalyst used was SZ promoted with iron and manganese. An yield of $46 \mathrm{wt} . \%$ iso-C4 was obtained at a pressure of about 103 bar and a temperature of $161^{\circ} \mathrm{C}$.

The beneficial effect of supercritical processing on the catalyst stability is qualitatively ascribed to a better solubility of deactivating organic deposits in the supercritical fluid [8,9]. The quantitative assessment of the effect of fluid density on the performance of heterogeneous catalysts, however, would require systematic studies of both, the kinetics of reaction and of transport processes, thereby taking altering thermodynamic states including changes of the distribution coefficients of compounds into account. Generally, research in this field is in a very early state, and no studies have been reported concerning the isomerisation of $n$-butane, so far.

On the longer term, our work is aimed at the quantitative description of a supercritical isomerisation process. Here, we present the first part of our study. Using commercially available extrudates of alumina-bound, non-promoted SZ as a base-case catalyst, we first focused on the identification of the operation conditions governing catalyst stability in order to find a suitable operational window for the assessment of the kinetics. The results are preliminary in that the catalyst has not been optimised at all. Some general trends, however, can already be distilled out at this stage that enable us to highlight potential benefits and to address problems that need to be solved.

\section{Experimental}

Sulphated zirconium hydroxide (MEL Chemicals, MEL XZO707/03) extrudates were calcined for $3 \mathrm{~h}$ at $600^{\circ} \mathrm{C}$. The resulting SZ catalyst had a surface area of $125 \mathrm{~m}^{2} / \mathrm{g}$ (Micromeritics ASAP 2010) and a pore volume of $0.25 \mathrm{~cm}^{3} / \mathrm{g}$. The sulphur content amounted to $2.6 \mathrm{wt} . \%$ and the amount of alumina binder was about $20 \mathrm{wt} . \%$. The magnitudes of the weight hourly space velocities and residence times reported refer to the total mass of the catalyst including alumina.

The isomerisation of $n$-butane was studied in a continuous flow unit (Fig. 1). The fixed bed reactor was made of stainless steel and had an internal diameter of $15 \mathrm{~mm}$ and a length of $350 \mathrm{~mm}$. The fixed bed consisted of $1.5-11.0 \mathrm{~g}$ of the calcined catalyst extrudates diluted with $\mathrm{SiC}$ (also used for packing up- and downflow to the catalyst). Prior to every conversion 


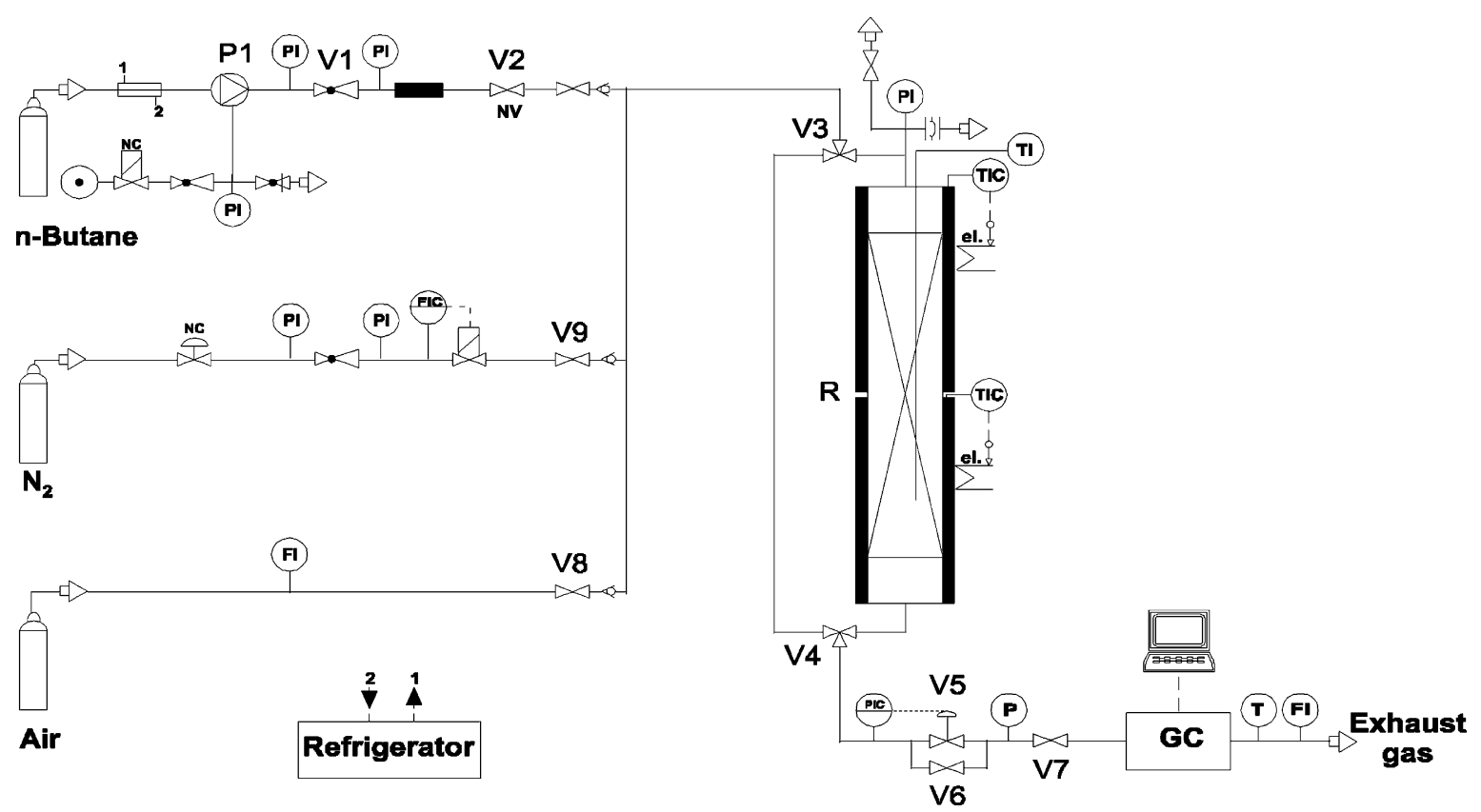

Fig. 1. Schematic representation of the experimental unit: P1, $n$-butane pump; V5, pressure control valve; R, reactor; GC, gas chromatograph.

experiment, the catalyst was activated in situ by heating for $2 \mathrm{~h}$ at $400{ }^{\circ} \mathrm{C}$ in flowing air $\left(73 \mathrm{~cm}^{3}(\mathrm{NTP}) / \mathrm{min}\right.$, Messer Griesheim, purity $99.999 \%)$. After cooling down to the desired reaction temperature in a flow of nitrogen $\left(73 \mathrm{~cm}^{3}(\mathrm{NTP}) / \mathrm{min}\right.$, Messer Griesheim, purity $99.996 \%$ ), the desired plant pressure was adjusted. Both reactor and by-pass line of the unit were first pressurised with nitrogen. Subsequently, the butane flow (Praxair, 99.5\% purity; major impurities: iso-C4, pentanes, propane; minor impurity: water $<5 \mathrm{ppm}$ ) was adjusted by use of the by-pass line, only. When stationarity was attained, the experiment was started by switching the fluid flow from the by-pass to the reactor line. Note that the butane feed was not further purified (water content $<5 \mathrm{ppm}$ ). Space velocities between 5 and $170 \mathrm{~h}^{-1}$ (modified residence time between 5000 and $70000 \mathrm{~kg} \mathrm{~s} / \mathrm{m}^{3}$ ) were installed by variation of the catalyst amount and butane flow rate. The effluent from the reactor was analysed on-line with a Hewlett-Packard (HP 6890) gas chromatograph (GC) equipped with an FID and a STABILWAX capillary column (crossbond carbowax, Restek) of $0.25 \mathrm{~mm}$ diameter and $60 \mathrm{~m}$ length.
$n$-Butane has a critical temperature of $152^{\circ} \mathrm{C}$ $(425 \mathrm{~K})$, a critical pressure of 38 bar and a critical density of $228 \mathrm{~kg} / \mathrm{m}^{3}$. In Fig. 2, the density of pure $n$-butane as a function of the pressure is depicted for four different temperatures. Near the critical point (where the dotted line, indicating the critical temperature, coincides with the vertical line, indicating the

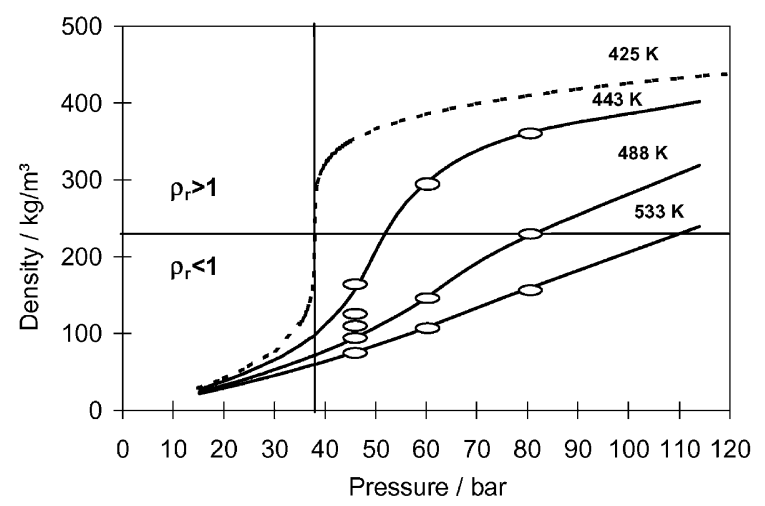

Fig. 2. Influence of temperature and pressure on the density of n-butane. 
critical pressure), the density strongly changes with pressure. Above the critical temperature, the effect of the pressure on the density is less pronounced. In our study, reaction temperatures ranged between 170 and $260{ }^{\circ} \mathrm{C}$ and total pressures were varied between 46 and 81 bar. In Fig. 2, the discrete experimental conditions applied are indicated by open ellipses. The corresponding reduced densities $\rho_{\mathrm{r}}$ range from subto supercritical values, i.e., from 0.33 to 1.58 ., but it should be stressed that the complete operational regime $(p, T)$ is supercritical. Within this regime, also mixtures of $n$-butane with reaction products (iso-C4, propane, and pentanes) are homogeneous and supercritical. Densities of such mixtures can be obtained on the basis of literature data and thermodynamical calculations.

\section{Results and discussion}

\subsection{Catalyst performance at supercritical conditions}

Typical plots of the conversion versus the runtime at $215^{\circ} \mathrm{C}$ are depicted in Fig. 3. As can be seen, there occurs no deactivation, irrespective of pressure and space velocity. The time range under investigation is too short, still, to speculate about the long-term stability. However, the same catalyst deactivated within some minutes in comparative experiments under gas-phase conditions. The data in Fig. 3 also show that higher conversions are reached at constant weight

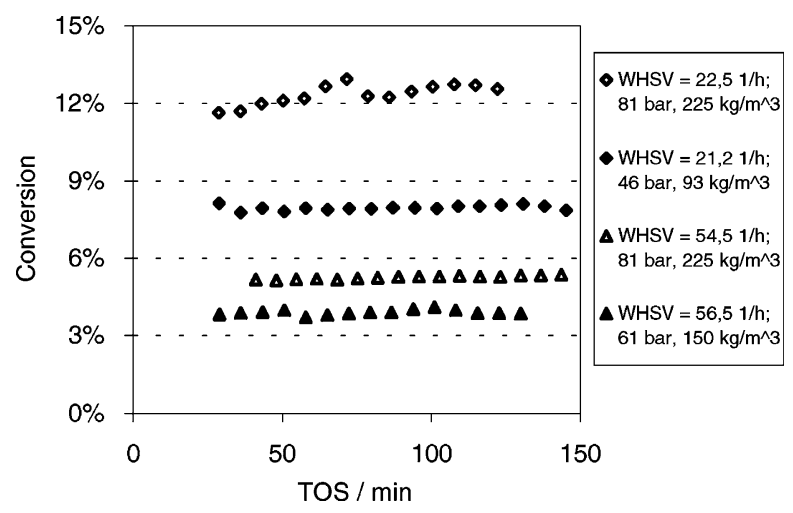

Fig. 3. Conversion at $215^{\circ} \mathrm{C}$ and different space velocities and pressures (fluid densities as indicated).

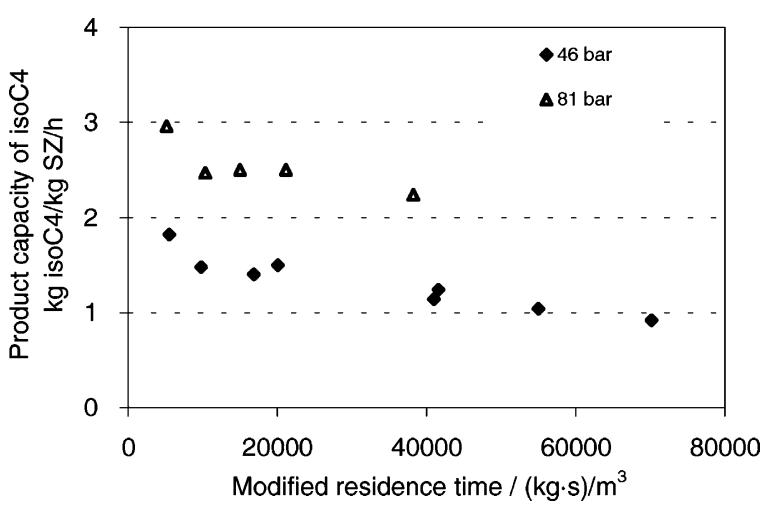

Fig. 4. Production capacity of iso-C4 versus modified residence time at $215^{\circ} \mathrm{C}$ and different pressures.

hourly space velocity when the pressure is increased. The reason is simply that equal weight hourly space velocities correspond to different residence times (here catalyst mass divided by the volumetric flow at reaction temperature and pressure) when the fluid density is changed. Hence, the plots in Fig. 3 should not be interpreted in terms of an effect of the butane concentration on the kinetics. They only show that the catalyst is stable at different feed loads. It should be noted that the purity of the $n$-butane used was equivalent to technical grade and no effort was made to remove traces of olefins that might be present. It is known that olefins enhance both, the initial isomerisation rate and the catalyst deactivation rate at gas-phase conditions [10]. To study the effect of olefinic feed species at supercritical conditions, further experiments are necessary.

With the catalyst used in our study, equilibrium conversions of $n$-butane (e.g., $55 \%$ at $215^{\circ} \mathrm{C}$ ) could not be achieved. With pure, undiluted $n$-butane, the maximum conversion observed in our experiments amounted to about $20 \%$. It appears, therefore, that the activity of this catalyst is not very high. The selectivities to iso-C4 varied between 73 and $93 \%$ in the temperature range $170-260{ }^{\circ} \mathrm{C}$. However, because of the high fluid densities at supercritical conditions, the achievable production capacity of iso- $\mathrm{C} 4$, defined as mass flow rate of iso-C4 out of the reactor per total mass of SZ extrudates, can be relatively high. This is demonstrated in Fig. 4. The data shown there were obtained at two different pressures and at a constant temperature of $215^{\circ} \mathrm{C}$. The production capacities 
obtained at supercritical conditions were found to be at least a factor of 10 higher than those obtained at atmospheric pressure (gas phase) under the most beneficial circumstances.

\subsection{Operational limitations}

While pressure or density had no effect on the catalyst stability, as shown above, the reaction temperature was found to be a decisive parameter. At temperatures above $235^{\circ} \mathrm{C}$, hydrogen sulphide could be detected in the reactor effluent and the conversion markedly decreased with time on stream. Analyses of spent catalysts confirmed the sulphur loss, e.g., 10\% of the original sulphur content within $2.5 \mathrm{~h}$ on stream at $533 \mathrm{~K}$ reaction temperature. In addition, the colour and the measured carbon content of the spent catalysts indicated that coke deposition is also enhanced at elevated temperatures. We assume that both, desulphurisation and coke deposition, contribute to the catalyst deactivation that is observed at temperatures above $235^{\circ} \mathrm{C}$. This operational limit can be considered as a serious disadvantage, however, low temperatures are also more favourable in view of the thermodynamics of the isomerisation reaction. Therefore, attempts to improve the catalyst would aim for higher activity at lower temperatures rather than for a better stability at high temperatures.

At constant temperature, the variation of pressure results not only in a change of the density but also in a change of the concentration. For this reason, mixtures of $n$-butane with propane were also processed to study the effect of concentration at constant temperature and density. Propane is a suitable diluent because it is not reactive at the process conditions applied. Fig. 5 shows the conversion of $n$-butane at $215^{\circ} \mathrm{C}$ and a reduced density of 0.42 for different feed concentrations. The data show that higher conversions are attained at lower $n$-butane concentrations, and that there is only a slight increase in conversion observable with increasing residence time. Because possible effects of mass transfer resistances could be excluded experimentally and by estimating Sherwood and Weisz numbers, we assume that surface or site saturation is responsible for the decrease in apparent activity with increasing reactant concentration. A detailed kinetic analysis is in progress. In addition, modifications of the parent catalyst are currently tested to find out

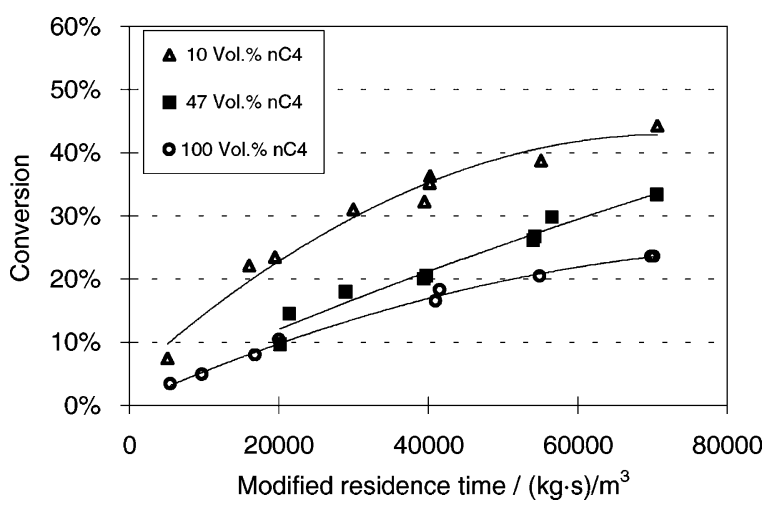

Fig. 5. Conversion at $215^{\circ} \mathrm{C}$ versus modified residence time and different butane concentrations.

which processes (e.g., reaction or desorption) are rate limiting.

\section{Conclusions}

The supercritical isomerisation of $n$-butane was successfully carried out over commercial catalysts extrudates containing SZ without promotors or platinum. Steady-state conversions for at least $150 \mathrm{~min}$ TOS were realised without co-feeding hydrogen. Production capacities of iso-C4 were much higher than at atmospheric conditions and amounted up to $3.0 \mathrm{~kg}$ iso-C4/ $\mathrm{kg}$ of catalyst and hour.

Increasing fluid densities result in higher throughputs and higher iso-C4 production capacities. On the other hand, the conversion decreases because the catalyst exhibits saturation behaviour. Hence, with the parent catalyst, high production capacities are not only coupled with higher costs for compression but also result in larger recycle streams.

Low reaction temperatures are thermodynamically favourable to obtain high yields of iso-C4. In addition, an upper temperature limit exists at $235^{\circ} \mathrm{C}$, above which the catalyst is deactivating due to desulphurisation, and highly toxic and corrosive hydrogen sulphide is released.

Both, the saturation behaviour at high butane concentrations and the sulphur loss at high temperatures call for an improvement of the catalyst properties, in particular, with respect to activity. Furthermore, future processing experiments must be devoted to the 
long-term stability and to the study of feed effects involving contaminants that are typically present in steam cracker or refinery effluents.

It is obvious that many topics need to be addressed, yet, and it is not possible to decide whether supercritical isomerisation can be considered as an efficient and environmentally more suitable process option at this point in time. The results obtained so far, however, justify an intensification of the research efforts in this interesting area of catalysis and process engineering.

\section{Acknowledgements}

The authors thank the German Research Foundation (DFG) for financial support and MEL Chemicals for providing the catalyst.

\section{References}

[1] D. Rosati, in: R. Meyers (Ed.), Handbook of Petroleum Refining Processes, McGraw-Hill, New York, 1986.

[2] K.J. Ware, A.H. Richardson, Hydrocarbon Process. 51 (1972) 161.

[3] H.W. Grote, Oil Gas J. 56 (1958) 73.

[4] C. Gosling, R. Rosin, P. Bullen, T. Shimizu, T. Imai, Petroleum Technol. Quart. 2 (1997-1998) 55.

[5] P.R. Sarathy, G.S. Suffridge, Hydrocarbon Process. 2 (1993) 43.

[6] Z. Hong, K.B. Fogash, J.A. Dumesic, Catal. Today 51 (1999) 269.

[7] M.V. Bhinde, C.Y. Hsu, Isomerisation of hydrocarbons with solid superacid catalyst at supercritical or near critical conditions, EP 0532153A2 (1993).

[8] S. Saim, B. Subramaniam, J. Catal. 131 (1991) 445.

[9] D.M. Ginosar, B. Subramaniam, Stud. Surf. Sci. Catal. 88 (1994) 327.

[10] S.Y. Kim, J.G. Goodwin Jr., D. Galloway, Catal. Today 63 (2000) 21. 